\title{
Does Postural Feedback Reduce Musculoskeletal Risk?: A Randomized Controlled Trial
}

\author{
Coral Oliver Hernández ${ }^{1, * \mathbb{D}}$, Shimeng Li ${ }^{2} \mathbb{D}$, María Dolores Merino Rivera $^{1}$ \\ and Inmaculada Mateo Rodríguez ${ }^{3,4,5}$ iD
}

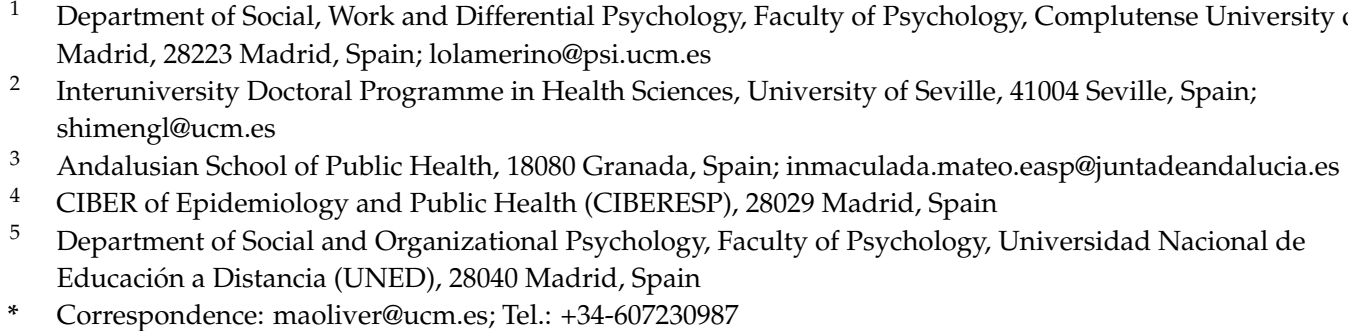

Citation: Oliver Hernández, C.; Li, S. Merino Rivera, M.D.; Mateo

Rodríguez, I. Does Postural Feedback Reduce Musculoskeletal Risk?:

A Randomized Controlled Trial. Sustainability 2022, 14, 583. https://

doi.org/10.3390/su14010583

Academic Editors: Julio Blanco,

Emilio Jimenez, Francisco

Flor-Montalvo and

Giuseppe Battaglia

Received: 11 November 2021

Accepted: 31 December 2021

Published: 5 January 2022

Publisher's Note: MDPI stays neutral with regard to jurisdictional claims in published maps and institutional affiliations.

Copyright: () 2022 by the authors Licensee MDPI, Basel, Switzerland. This article is an open access article distributed under the terms and conditions of the Creative Commons Attribution (CC BY) license (https:// creativecommons.org/licenses/by/ $4.0 /)$.

\begin{abstract}
Background: There is a high prevalence of musculoskeletal disorders among personnel working in the healthcare sector, mainly among nursing assistants and orderlies. Objective: The objective is to analyze the effectiveness of a multi-component intervention that included postural feedback in reducing musculoskeletal risk. Method: A total of 24 nursing assistants and orderlies in a hospital setting were randomly assigned to an intervention group or a control group. After collecting sociodemographic information, a selection of tasks was made and assessed using the REBA (rapid entire body assessment) method. A multi-component intervention was designed combining theoretical and practical training, including feedback on the postures performed by the professionals involved, especially those involving high musculoskeletal risk. This program was applied only to participants in the intervention group. Subsequently, eight months after the first assessment and intervention, the second assessment was carried out using the same method and process as in the first evaluation. Results: The results indicate that the musculoskeletal risk in the second assessment in the intervention group was significantly reduced. However, no significant changes were observed in the control group. Conclusion: The multi-component intervention applied can significantly reduce the musculoskeletal risk of nursing assistants and orderlies. In addition, it is a low-cost intervention with great applicability.
\end{abstract}

Keywords: postural feedback; intervention program; patient handling; musculoskeletal disorders; nursing assistants

\section{Introduction}

Healthcare workers are exposed to different risk factors that can lead to musculoskeletal disorders (MSD); physical and biomechanical factors [1,2], individual factors [3-5], organizational and psychosocial factors [6,7] are more frequent. According to the World Health Organization [8], such disorders are a health problem that severely affects work capacity, social life and leads to early retirement. All this increases both personal and social costs and has a great impact on the health of these professionals. In fact, according to the study by Lezin and Walkins Castillo [9], 50\% of American adults suffer from musculoskeletal disorders. Similarly, in Europe, MSD is one of the main reasons for absenteeism, leading to the decreased profitability of companies and a substantial increase in social security costs [10].

Different studies show that MSDs have a higher incidence among nurses and nursing assistants than in other groups [11], ranging from $45 \%$ to $88 \%$, and most cases occur in 
more than one part of the body [12-17]. Typical features of this disorder are pain (usually persistent pain) and limitation of mobility and dexterity, as well as decreased functions in the affected parts of the body. Such problems usually affect mainly the back, shoulders, neck and upper extremities [18].

The individual variables that have been found to be relevant in this type of study, according to a 2020 report by the European Agency for Safety and Health at Work (EUOSHA) [19], are age, where older people are more exposed to such problems, and gender, with women having a higher prevalence.

It has been proven that MSDs are related to both sudden exposure to poor posture and to repetitive movements of long duration [20]. As confirmed by Nourollahi et al. [21], on one hand, nursing work involves frequent and extremely awkward postures (trunk flexion $\geq 45^{\circ}$ and lateral bend $\geq 20^{\circ}$ ), which are potential risk factors for MSDs. On the other hand, the duration of exposure to awkward postures also increases the musculoskeletal risk. In activities related to patient handling, the professional usually adopt a forward trunk flexion posture for an average of two hours per shift. This time period increases as patients' needs increase or the number of workers decreases [22].

For nursing assistants that require manual handling of patients in daily work, high physical demands are the main risk factor leading to MSD [23]. Awkward posture clearly increases musculoskeletal risk [24,25]. However, a large percentage of workers are unaware of harmful postures in their workplace [26].

Several studies have shown that it is essential not only to analyze the associated risk factors, but also to analyze the appropriate intervention strategies to reduce and prevent MSDs in each group according to their particular needs [27-29].

In recent years, different intervention strategies have been designed. We can mention, among others, the use of mechanical aids (mechanical full-body lifts, sit-to-stand lifts and lateral-transfer devices, etc.) [30,31], additional breaks [32], physical exercise and stretching [33], training, distribution of instructional materials [34] and physical therapy [35] to prevent MSDs or alleviate pain.

There are studies that show that an intervention program based on ergonomic posture training for task performance is effective in changing harmful postural habits [36-39]. Other studies indicate that multi-component interventions have shown good results [40-44]. However, although some intervention programs have had some positive effects such as short-term pain reduction [35,45-47], overall, evidence was limited to determine the effectiveness of any of these intervention strategies [48,49].

Therefore, the present study aims to analyze the effectiveness of a multi-component intervention program, based on theoretical training, patient handling techniques, warmup and stretching exercises and feedback of the postures performed by the professionals involved to reduce musculoskeletal risks.

\section{Materials and Methods}

\subsection{Settings and Design}

A randomized controlled trial design was used. The subjects were nurse assistants and orderlies from two different service units in a hospital in southern Spain. The supervisor of each service unit reported and recruited the participants; one investigator from the team numbered the subjects and used SPSS software (SPSS Inc., Chicago, IL, USA) to generate a random sequence, and the second investigator randomly assigned $50 \%$ of them to the intervention group (IG) and 50\% to the control group (CG). The two researchers worked independently. The research was conducted from early May 2019 to the end of December 2019. First, a musculoskeletal risk assessment was performed using the REBA method, then the intervention actions were designed and implemented. All participants were reevaluated 8 months later using the same assessment method.

To preserve allocation concealment, the sequence described below was followed to randomly assign people to the IG or CG: (a) A list was made of the people who met the criteria to be included in the study; (b) each person was given a code so that each 
potential participant was anonymous; and (c) using a random number table, each person was allocated to either the intervention group or the control group. This allocation was done by a person on the research team who, nevertheless, did not participate in the assessment or in the intervention in this study nor in any phase of the later gathering of information.

Neither the researchers in charge of doing the initial assessment nor the participants knew of the next allocation in the sequence. That is to say, the participants did not know if they were going to be part of the IG or the CG when the pre-intervention assessment was done.

\subsection{Participants}

The participants are orderlies and nursing assistants who are directly responsible for the tasks associated with patient handling in their daily work. The research was carried out in two service units: internal medicine and neurology were selected for having a large number of bedridden and functionally dependent patients. The professionals who work there perform complex and frequent patient-handling tasks.

Before starting the study, the researchers asked the person in charge of each service unit for a list of potential samples and estimated the sample size based on the following inclusion criteria:

(a) Professional category is nursing assistant or orderly.

(b) The main daily tasks involve patient handling.

(c) Be on duty on the date of data collection and intervention.

And exclusion criteria:

a. With temporary contracts of less than eight months.

b. Participating in other intervention projects simultaneously.

c. Not working on evaluation and intervention days, sick leave, or vacation.

According to the information provided by the hospital's occupational risk prevention department, the total number of nursing assistants or orderlies is 42 (27 in internal medicine and 15 in neurology). Of these, 26 met the inclusion criteria. Six people were excluded because they did not involve patient handlings in daily tasks, and ten people were excluded because they did not work during the study period.

People who met all of the eligibility criteria were all invited to participate in the study. We distributed a sociodemographic questionnaire and informed consent form through their direct managers (the supervisor of nursing assistants and the services director of orderlies). In the end, 24 people agreed to participate. The response rate was $92.3 \%$. Those who volunteered to participate in the project were randomly assigned to an intervention group (IG) or a control group (CG). The distribution of these participants by gender, age, height, weight, BMI, professional category, service unit and work experience can be seen in Table 1. Of those who agreed to participate, eight participants from the IG and nine from the CG completed the post-assessment at eight months. Figure 1 shows the participation flowchart.

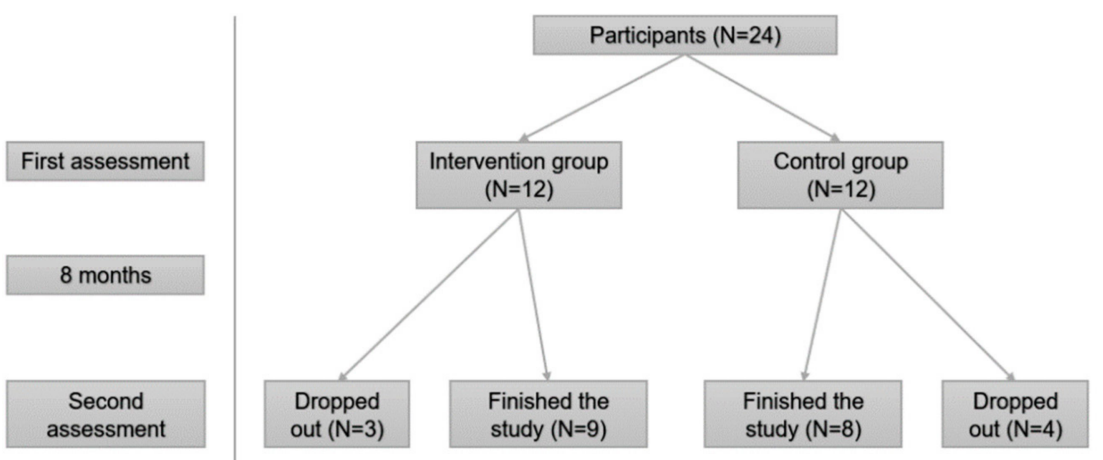

Figure 1. Participation flowchart of study. 
Table 1. Comparison of sociodemographic characteristics of participants in CG and IG in the preand post-assessment.

\begin{tabular}{|c|c|c|c|c|c|c|c|c|c|c|c|c|}
\hline \multirow[b]{2}{*}{ Variable $^{a}$} & \multicolumn{6}{|c|}{ Pre-Assessment } & \multicolumn{6}{|c|}{ Post-Assessment } \\
\hline & Group & $\mathbf{N}^{\mathbf{b}}$ & Mean & \multicolumn{2}{|c|}{$\mathrm{SD}^{\mathrm{c}}$} & $p$-Value ${ }^{\mathrm{d}}$ & Group & $\mathbf{N}^{\mathbf{b}}$ & Mean & $\mathrm{SD}^{\mathrm{c}}$ & \multicolumn{2}{|c|}{$p$-Value ${ }^{\mathrm{d}}$} \\
\hline \multirow{2}{*}{ Age (years) } & Intervention & 12 & 52.67 & \multirow{2}{*}{\multicolumn{2}{|c|}{$\begin{array}{l}8.424 \\
4.122\end{array}$}} & \multirow[t]{2}{*}{0.927} & Intervention & 9 & 53.67 & 6.1 & \multirow{2}{*}{\multicolumn{2}{|c|}{0.537}} \\
\hline & Control & 12 & 52.42 & & & & Control & 8 & 51.38 & 8.77 & & \\
\hline \multirow{2}{*}{$\begin{array}{c}\text { Work } \\
\text { Experience } \\
\text { (years) }\end{array}$} & Intervention & 12 & 16.67 & \multicolumn{2}{|c|}{3.798} & 0.819 & Intervention & 9 & 15.78 & 8.04 & \multicolumn{2}{|c|}{0.975} \\
\hline & Control & 12 & 16.08 & \multicolumn{2}{|c|}{7.81} & & Control & 8 & 15.88 & 3.72 & \\
\hline \multirow{2}{*}{ Height (cm) } & Intervention & 12 & 161.42 & \multirow{2}{*}{\multicolumn{2}{|c|}{12.124}} & 0.686 & Intervention & 9 & 163.22 & 13.56 & \multirow{2}{*}{\multicolumn{2}{|c|}{0.89}} \\
\hline & Control & 12 & 163.08 & & & & Control & 8 & 162.5 & 5.4 & & \\
\hline Weight (kg) & Intervention & 12 & 67.33 & \multicolumn{2}{|c|}{9.884} & 0.648 & Intervention & 9 & 66.44 & 10.93 & \multirow{2}{*}{\multicolumn{2}{|c|}{0.474}} \\
\hline & Control & 12 & 65.33 & \multicolumn{2}{|c|}{11.236} & \multirow{3}{*}{0.385} & Control & 8 & 70 & 8.7 & & \\
\hline BMI & Intervention & 12 & 25.81 & \multirow{2}{*}{\multicolumn{2}{|c|}{$\begin{array}{l}3.20565 \\
3.40255\end{array}$}} & & Intervention & 9 & 25.14 & 4.2 & \multirow{2}{*}{\multicolumn{2}{|c|}{0.452}} \\
\hline \multirow[t]{2}{*}{ (weight/height ${ }^{2}$ ) } & Control & 12 & 24.61 & & & & Control & 8 & 26.48 & 2.7 & & \\
\hline & & \multicolumn{2}{|c|}{$\begin{array}{c}\text { Control Group } \\
(n \%)\end{array}$} & \multicolumn{2}{|c|}{$\begin{array}{c}\text { Intervention Group } \\
(n \%)\end{array}$} & $p$-Value ${ }^{\mathrm{e}}$ & & \multicolumn{2}{|c|}{ Control Group ( $n \%)$} & \multicolumn{2}{|c|}{$\begin{array}{l}\text { Intervention } \\
\text { Group }(n \%)\end{array}$} & $p$-Value ${ }^{\mathrm{e}}$ \\
\hline \multirow[t]{2}{*}{ Gender } & Male & 2 & $16.67 \%$ & 3 & $25.00 \%$ & \multirow[t]{2}{*}{0.5} & Male & 1 & $10.00 \%$ & 3 & $28.57 \%$ & 0.312 \\
\hline & Female & 10 & $83.33 \%$ & 9 & $75.00 \%$ & & Female & 7 & $90.00 \%$ & 6 & $71.43 \%$ & \\
\hline \multirow{2}{*}{$\begin{array}{l}\text { Professional } \\
\text { Category }\end{array}$} & Orderly & 4 & $33.33 \%$ & 4 & $33.33 \%$ & \multirow[t]{2}{*}{0.667} & Orderly & 2 & $20.00 \%$ & 4 & $42.86 \%$ & 0.402 \\
\hline & $\begin{array}{l}\text { Nursing } \\
\text { assis- } \\
\text { tants }\end{array}$ & 8 & $66.67 \%$ & 8 & $66.67 \%$ & & $\begin{array}{l}\text { Nursing } \\
\text { assis- } \\
\text { tants }\end{array}$ & 6 & $80.00 \%$ & 5 & $57.14 \%$ & \\
\hline \multirow{2}{*}{ Service Unit } & $\begin{array}{l}\text { Internal } \\
\text { Medicine }\end{array}$ & 5 & $41.67 \%$ & 5 & $41.67 \%$ & 0.660 & $\begin{array}{l}\text { Internal } \\
\text { Medicine }\end{array}$ & 3 & $40.00 \%$ & 4 & $42.86 \%$ & 0.772 \\
\hline & Neurology & 7 & $58.33 \%$ & 7 & $58.33 \%$ & & Neurology & 5 & $60.00 \%$ & 5 & $57.14 \%$ & \\
\hline
\end{tabular}

a. Variables: Means and standard deviations (SD) are used to describe quantitative variables, and frequencies and percentages are used to describe qualitative variables. $b . \mathrm{N}=$ Number of recorded movements: the different movements of the same participant were collected and evaluated separately. c. SD = Standard deviation. d. Independent sample $t$ test. e. Chi-square test.

\subsection{Variables and Instruments}

(a) Sociodemographic variables

Sociodemographic data is collected from all participants in both groups (IG and CG) on: gender (male, female), age (years), height $(\mathrm{cm})$, weight $(\mathrm{kg})$, professional category (nursing assistants, orderly), work experience (year/s), service unit in which the work was performed (internal medicine, neurology). In addition, the body mass index (BMI) is constructed based on height and weight, categorized according to the definition of the National Institute of Health (NIH) and the World Health Organization (WHO) [50]. The instrument used to collect the above variables is a self-administered questionnaire.

(b) Variables on musculoskeletal risk

The ergonomics experts recorded the following conditions before assessing the movements: (a) type of tasks (patient mobilization towards the head of the bed, postural change, transfer from bed to chair/wheelchair and transfer from chair/wheelchair to bed); (b) availability of a height-adjustable bed (yes, no); (c) use of mechanical aids such as patient lifts (yes, no).

In order to assess the postural risk, the REBA (rapid entire body assessment) method [51] was used, a method that has a high intra-rater reliability $(I C C=0.925)$ for REBA raw scores and moderate inter-rater reliability $($ IRR) (Fleiss kappa $=0.54)$ for a categorical scoring of REBA. [52]. Based on the Spanish version of the REBA measurement tool [53], we designed a paper worksheet that was easy to use to collect information. This method allows the obtention of a global risk level through the scores of different parts of the body. Specifically, the overall score is determined by the score of group A (between 1 and 12, assesses trunk, neck, legs, load or strength), and group B (between 1 and 12, assesses arms, forearms, wrists, grip quality) [54]. The overall score ranges from 1 to 15 . The higher the score, the higher the postural risk and the greater the urgency of the intervention.

The REBA method evaluates not only the flexion, extension and twisting of body parts but also loads and forces. It also has the assessment of the quality of grip (good, fair, bad, unacceptable) and takes into account the impact of the body when remaining static for a long time, sudden changes in load or being in an unstable posture. In this regard, it is a particularly suitable method for assessing tasks associated with the mobilization of patients [55-57]. 


\subsection{Intervention Program}

The research team designed and implemented a multi-component intervention plan in the IG in which the following can be distinguished: (1) theoretical training on ergonomics and MSD, (2) patient handling techniques, (3) warm-up and stretching exercises and (4) personalized postural feedback based on the recorded videos of each subject.

Due to the particular characteristics of the profession of nursing assistants and orderlies, the intervention was performed several times over two days during working hours. The number of participants in each training session was one to three, so that the absence of the professionals would not have serious consequences on patient care. Three ergonomics experts as trainers jointly provided theoretical knowledge, patient handling techniques and warm-up and stretching exercises, as well as personalized postural feedback. Except for the postural feedback part, which is customized according to the posture of each participant, the rest of the content is the same for different sessions. All sessions are taught by the same trainers.

The intervention took place in a specific room provided by the hospital. The material used included slide-presentation equipment, a bed of the same model used by the patients, a chair and wheelchair and mechanical aids such as a patient lift.

Specifically, the following intervention actions were carried out:

Theoretical training (10 min): Since all participants have years of work experience in the healthcare sector and have knowledge related to patient mobilization, the content of the theoretical training focused on ergonomics and MSDs, including the current status of the prevalence of MSD in the healthcare sector, the main symptoms, various risk factors and the importance of ergonomics in the prevention of MSDs.

Patient-handling technique (15 min): First, participants were taught to avoid the most harmful postures for the body in order to reduce the risk of MSD. The content included but was not limited to the following actions to be taken when performing patient handling tasks: (1) separation of the feet and placing one foot slightly in front of the other to provide a stable support base; (2) when conditions permit, adjusting the height of the bed to the hip; (3) keeping the back straight and leaning forward slightly; (4) staying close to the patient's body and reducing the bending angle of the torso; (5) contracting the abdomen and hip muscles to stabilize the pelvis; (6) bending the legs slightly and using the strength of the thigh muscles to avoid excessive weight-bearing on the knees; (7) using the center of gravity instead of the waist to stretch back when pulling backwards; (8) when the action involves turning, using small steps to avoid the excessive twisting of the knee joint and spine; (9) using mechanical aids and/or cooperation with other partners as much as possible; (10) when the patient is overweight, using mechanical aids. Secondly, the researchers also taught them how to use mechanical aids correctly, according to the machine model, and the precautions when using them.

Warm-up and stretching exercises $(5 \mathrm{~min})$ : We taught the participants and recommended that they did a set of warm-up exercises before starting work, which were basic and simple dynamic exercises for the neck, chest, back, legs, shoulders, arms and wrists. Similarly, we also taught them static stretching exercises and advised them to practice it during breaks and after work. It has been proven that warm-up and stretching exercises can improve muscle strength and body flexibility, strengthen postural control and decrease MSD symptoms [58-61]. It was recommended to warm up before starting work and to perform stretching exercises during breaks and after work.

Postural feedback (20 min): This is the most novel and special part of the whole intervention project. The participants were shown a selection of the postures recorded during the tasks, followed by self-reflection and conclusions based on knowledge from the theoretical and practical training provided. The researchers then gave each subject postural feedback from an ergonomic perspective on two aspects: recognition of positive points in mobilization and the identification of areas for improvement (positive feedback). In other words, they not only pointed out what they needed to improve by explaining why but also indicated the correct behavior to develop in the future. 
The control group did not receive any type of intervention prior to the second assessment. For ethical reasons, the control group was offered the same intervention once the post-assessment was completed.

\subsection{Data Collection Procedure}

First of all, the hospital management was contacted; the service units most exposed to this type of risk were selected and authorization was requested from each department. Once the units were determined, the purpose of the study was explained to each of the supervisors of each unit, and we thus obtained a final list of participants and sent them a summary of the purpose of the research, together with the informed consent form for their participation (see Section 2.6 on ethical approval).

Subsequently, a questionnaire of sociodemographic variables was distributed to the participants. Prior to initiating any observation and recording, permission and informed consent was obtained from the patients.

In the study, data collection was performed by three previously trained experts with high inter-rater validation. The postures were analyzed by two of them at the time of observing the mobilization of the patients, and the third expert was dedicated to their recording to give them personalized postural feedback during the intervention sessions and to verify each assessment obtained. In order to increase the objectivity and accuracy of the evaluation results, interjudgment verification was adopted for all cases. Two researchers conducted independent evaluations and then compared the results. If there was a discrepancy, a third researcher joined. The three researchers observed the recorded video, discussed it in groups and finally reached an agreement.

Four different types of patient-handling movements were evaluated, namely the mobilization of the patient to the headrest, postural change, transfer from bed to chair/wheelchair and transfer from chair/wheelchair. The number of movements collected depends on the number of patients and the content of the work on the assessment days.

Then, once the data and the recorded videos were analyzed, the intervention programs were carried out, and eight months later, the post-assessment was made for the subjects of two groups IG and CG, applying the same data-collection procedure as in the pre-assessment.

\subsection{Ethical Approval}

The study was conducted in accordance with the Declaration of Helsinki and approval was obtained from the Andalusian Research Ethics Committee (REC of the Virgen MacarenaVirgen del Rocio university hospitals: d9b449426c41062448a2d8be713a0b063741ae96).prior to the study. In all cases, informed consent and written authorization were requested in advance from the professionals and the patients involved or their relatives if they were not of sound mind, clearly explaining that no name or video image could be identified, always guaranteeing the privacy of the participants.

\subsection{Data Analysis}

The computerized statistical package SPSS 25.0 (SPSS Inc., Chicago, IL, USA) was used for the analysis of the results. To eliminate the influence of participant compliance on the evaluation of the effectiveness of the intervention, per-protocol (PP) analysis and intention-to-treat (ITT) analysis were used. Verification of normality was analyzed using the Shapiro-Wilk test. Since the data did not have a normal distribution and the sample size had a low $\mathrm{N}$, it was decided to use nonparametric contrast tests. To compare REBA scores between IG and CG, the Mann-Whitney U test was used. For the intra-group comparison, that is, between the results of the pre-assessment and post-assessment, the Wilcoxon signed-ranks test was used. Finally, the main effect and interaction effect was analyzed using repeated-measures ANOVA. All tests are considered statistically significant when the $p$-value is $<0.05$. 


\section{Results}

\subsection{The Sociodemographic Characteristics}

In the second assessment, a total of seven participants were not found due to change of shift, change of service unit or being on vacation at the time of this second assessment. Therefore, of the total of 24 nursing assistants and orderlies working in the two selected services, eight months later, it was possible to reassess 8 of the IG and 9 of the CG.

Descriptive statistics of the participants are shown in Table 1. The average age (SD) of the subjects in the total sample was 52.54 (SD \pm 6.487 ) years and, in the control group and the intervention group, was $50.8(\mathrm{SD}=7.91)$ years and $53.79(\mathrm{SD}=5.21)$ years, respectively. The average work experience of the control group was 15.70 years $(\mathrm{SD}=3.30)$, and the average work experience of the intervention group was 16.86 years (SD $=7.47$ ).

In the $t$-tests, there was no statistically significant difference between the two groups of subjects in any of the variables such as gender, age, BMI, professional category, service unit, years of work experience and type of tasks performed $(p>0.05)$. Therefore, both groups were equivalent. Similarly, as can be seen from Table 1, even if seven participants dropped out in the second assessment, the sociodemographic characteristics of the two groups were still equivalent.

\subsection{Per-Protocol (PP) Analysis}

In the first REBA data collection, a total of 56 movements were evaluated (8 patient mobilizations towards the head of the bed, 17 postural changes, 19 transfers from bed to chair/wheelchair and 12 transfers from bed to chair/wheelchair), of which 21 were performed by participants in the control group and 35 were performed by participants in the intervention group. In the second assessment with the REBA, carried out eight months later, a total of 46 movements were collected ( 7 patient mobilizations towards the head of the bed, 15 postural changes, 15 transfers from bed to chair/wheelchair and 9 transfers from bed to chair/wheelchair), of which 19 were performed by the control group and 27 were performed by the intervention group.

Regarding the comparison between pre- and post-assessment (Table 2), in the intervention group, the global score and the score of groups A and B achieved a significant decrease eight months after the intervention $(p<0.05)$. In the control group, no significant decrease was found. The distribution of REBA method scores from the two assessments of IG and CG are presented in Figure 2a,b. It can be clearly seen from the figure that the REBA scores of the intervention group generally decreased, while the REBA scores of the control group did not change.

Table 2. Comparison of pre- and post-evaluation within groups.

\begin{tabular}{|c|c|c|c|c|c|c|c|c|c|}
\hline \multirow[b]{2}{*}{ GROUP } & \multicolumn{4}{|c|}{ Pre-Assessment } & \multicolumn{4}{|c|}{ Post-Assessment } & \multirow{2}{*}{$\begin{array}{l}\text { Pre vs. Post } \\
p \text {-Value }\end{array}$} \\
\hline & $\mathbf{N}^{a}$ & REBA Score & Mean & $\mathrm{SD}^{\mathrm{b}}$ & $\mathbf{N}^{\mathbf{a}}$ & REBA Score & Mean & $S^{b}$ & \\
\hline \multirow[t]{2}{*}{ Control } & 21 & Global & 7.24 & 2.844 & 19 & Global after & 6.68 & 1.003 & 0.212 \\
\hline & $\begin{array}{l}21 \\
21\end{array}$ & $\begin{array}{l}\text { A before } \\
\text { B before }\end{array}$ & $\begin{array}{c}6.38 \\
4.9\end{array}$ & $\begin{array}{l}2.312 \\
1.044\end{array}$ & $\begin{array}{l}19 \\
19\end{array}$ & $\begin{array}{l}\text { A after } \\
\text { B after }\end{array}$ & $\begin{array}{l}5.74 \\
4.68\end{array}$ & $\begin{array}{l}0.872 \\
0.749\end{array}$ & $\begin{array}{l}0.182 \\
0.141\end{array}$ \\
\hline \multirow[t]{2}{*}{ Intervention } & 35 & $\begin{array}{l}\text { Global } \\
\text { before }\end{array}$ & 8.54 & 2.381 & 27 & Global after & 5.44 & 1.05 & $0.000^{* *}$ \\
\hline & $\begin{array}{l}35 \\
35\end{array}$ & $\begin{array}{l}\text { A before } \\
\text { B before }\end{array}$ & $\begin{array}{l}7.06 \\
5.26\end{array}$ & $\begin{array}{c}1.714 \\
1.4\end{array}$ & $\begin{array}{l}27 \\
27\end{array}$ & $\begin{array}{l}\text { A after } \\
B \text { after }\end{array}$ & $\begin{array}{l}4.81 \\
4.56\end{array}$ & $\begin{array}{l}0.736 \\
0.577\end{array}$ & $\begin{array}{l}0.000^{* *} \\
0.023 *\end{array}$ \\
\hline
\end{tabular}

a. $\mathrm{N}=$ Number of recorded movements: the different movements of the same participant were collected and evaluated separately. b. SD $=$ Standard deviation. c. Wilcoxon signed-ranks test ${ }^{*} p<0.05,{ }^{* *} p<0.01$.

Next, comparisons were made between the IG and the CG (Table 3). At the first assessment before the intervention, there were no significant differences between IG and CG in REBA scores. However, in the second assessment that took place eight months after the implementation of the intervention project, it was observed that the overall score of the IG was significantly better than that of the CG $(p<0.05)$. More specifically, the score of group A (between 1 and 12, assesses trunk, neck, legs, load or strength) in the IG was significantly better than that of the CG; the score of group B (between 1 and 12, 
assesses arms, forearms, wrists, grip quality) was better than that of the control group, but not significantly.

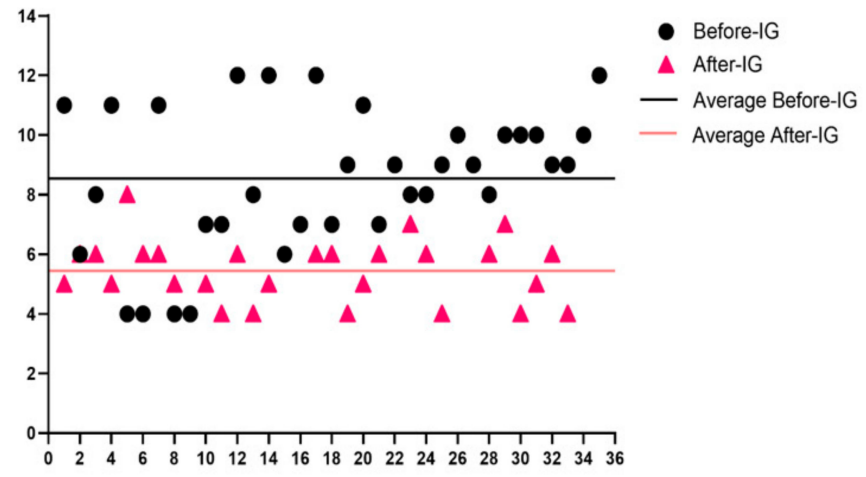

(a)

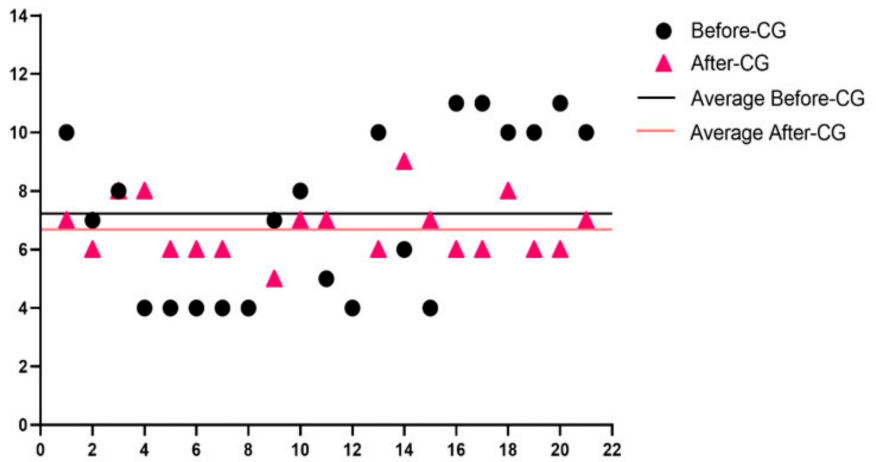

(b)

Figure 2. (a) Distribution of the REBA scores of two assessments in the intervention group (IG). (b) Distribution of the REBA scores of two assessments in the control group (CG).

Table 3. Comparison of REBA method scores between CG and IG.

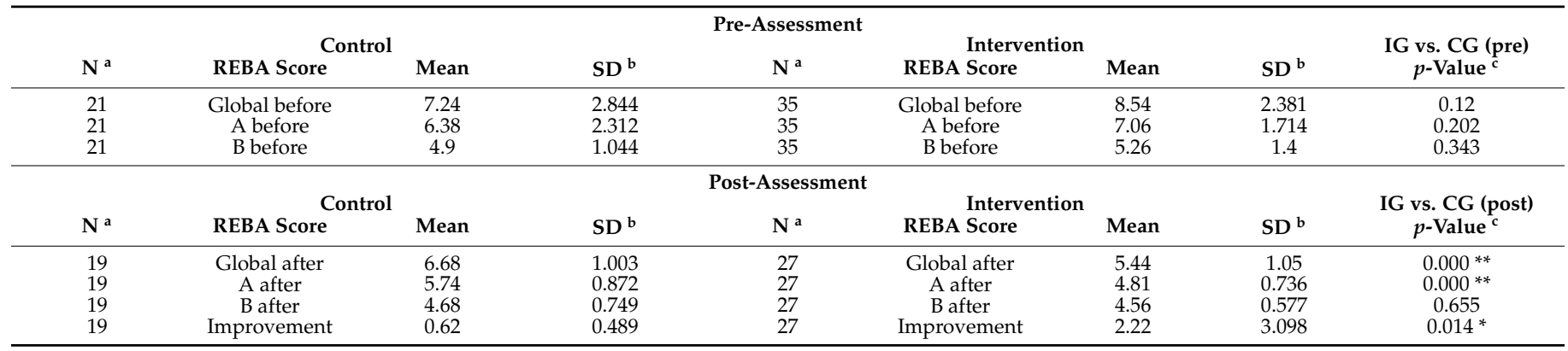

a. $\mathrm{N}=$ Number of recorded movements: the different movements of the same participant were collected and evaluated separately. b. SD $=$ Standard deviation. c. Mann-Whitney U test ${ }^{*} p<0.05,{ }^{* *} p<0.01$.

The overall REBA method score difference was calculated for the same individual for the same task before and after the intervention. The results showed that the average improvement in the intervention group was $2.22 \pm 3.098$, while, for the control group, it was $0.62 \pm 0.489$, with a significant difference $(p<0.05)$ (Table 3$)$.

Finally, the results of repeated-measures ANOVA (Figure 3) also indicated that there was a significant difference between the REBA scores at the two time points, pre and post $(p<0.01)$, but the interaction effect of the REBA*Group was not significant $(p>0.05)$.

\subsection{Intention-to-Treat (ITT) Analysis}

In the pre-assessment and post-assessment, the sociodemographic characteristics of the participants in the two groups were equivalent. All participants were included in this analysis to reduce the bias caused by missing data, regardless of whether the participants dropped out. The results are shown in Table 4 . In the post-assessment, the REBA scores (global, A and B) were significantly reduced in the intervention group. However, no significant difference was observed in the control group. This result is consistent with the per-protocol analysis. 


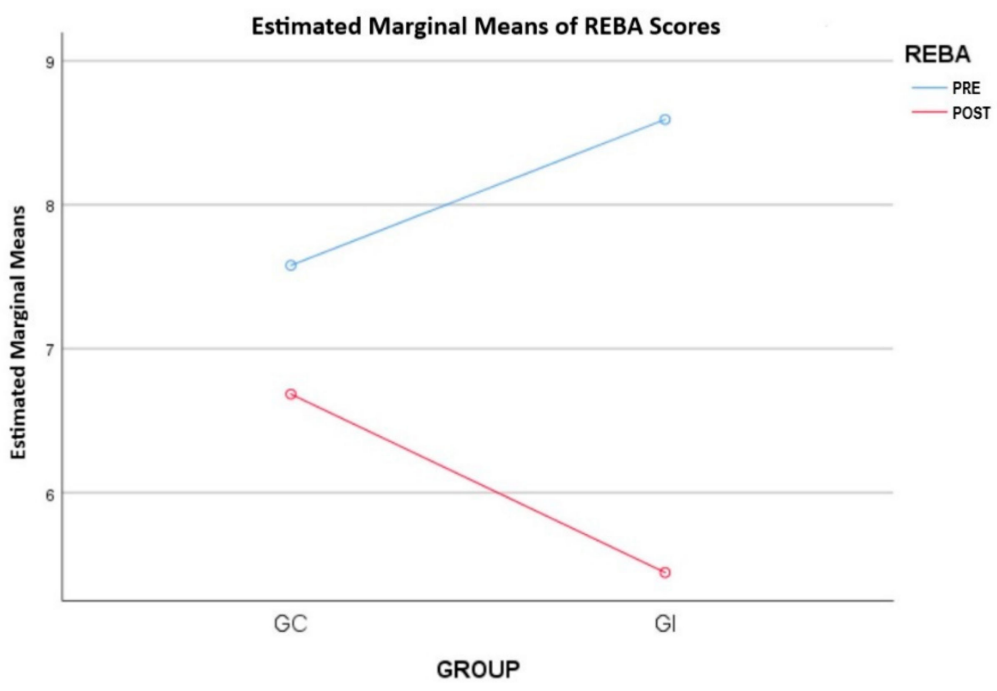

Figure 3. Estimated marginal means of the REBA scores of the two assessments before and after the intervention.

Table 4. Comparison of pre and post evaluation (Intention-to-treat analysis).

\begin{tabular}{|c|c|c|c|c|c|c|c|c|c|c|}
\hline \multirow[b]{2}{*}{ GROUP } & \multicolumn{4}{|c|}{ Pre-Assessment } & \multicolumn{4}{|c|}{ Post-Assessment } & \multicolumn{2}{|c|}{ Pre- vs. Post- } \\
\hline & $\mathbf{N}^{\mathrm{a}}$ & REBA Score & Mean & $\mathrm{SD}^{\mathrm{b}}$ & $\mathbf{N}^{\mathrm{a}}$ & REBA Score & Mean & $\mathrm{SD}^{\mathrm{b}}$ & $p$-Value ${ }^{c}$ & $p$-Value ${ }^{\mathrm{d}}$ \\
\hline \multirow[t]{3}{*}{ Control } & 21 & Global before & 7.24 & 2.844 & 21 & Global after & 6.43 & 1.248 & 0.212 & 0.212 \\
\hline & 21 & A before & 6.38 & 2.312 & 21 & A after & 5.48 & 0.981 & 0.141 & 0.141 \\
\hline & 21 & B before & 4.9 & 1.044 & 21 & B after & 4.62 & 0.669 & 0.179 & 0.179 \\
\hline \multirow[t]{3}{*}{ Intervention } & 35 & Global before & 8.54 & 2.381 & 35 & Global after & 6.11 & 1.937 & $0.000 * *$ & $0.000 * *$ \\
\hline & 35 & A before & 7.06 & 1.714 & 35 & A after & 5.23 & 1.352 & $0.000 * *$ & $0.000 * *$ \\
\hline & 35 & B before & 5.26 & 1.4 & 35 & B after & 4.74 & 0.852 & $0.035 *$ & 0.023 * \\
\hline
\end{tabular}

a. $\mathrm{N}=$ Number of recorded movements: the different movements of the same participant were evaluated separately. b. $\mathrm{SD}=$ Standard deviation. c. Wilcoxon Signed Ranks Test ${ }^{*} p<0.05,{ }^{* *} p<0.01$. d. Repeated measures ANOVA * $p<0.05,{ }^{* *} p<0.01$.

\section{Discussion}

The intervention plan developed in the study has yielded positive results in the reduction of musculoskeletal risk. This is consistent with the results of other multi-component intervention research in the healthcare sector $[42,47,62,63]$.

Reassessment after eight months of intervention showed that the musculoskeletal risk of the postures adopted by the nursing assistants and orderlies during manual patient mobilization decreased significantly and seemed to last over time. This shows that the intervention can help professionals with similar characteristics as our study to consciously adopt less harmful postures in their daily work. This is consistent with the results of other intervention programs $[57,64,65]$ that confirm that maintaining a correct posture in movement and correct postural training play a prominent role in the prevention of MSDs.

Theoretical and practical training in ergonomics has contributed positively to the effectiveness of the intervention plan. Numerous studies have confirmed that ergonomics training can reduce the risk of MSDs $[34,38,66]$. However, Ziam et al. noted that the MSD-prevention knowledge that nurses learned in university or vocational training is rarely applied in the actual job due to a lack of context [67]. This is why we decided to add postural feedback, so that participants could connect the theoretical and practical knowledge with themselves and their daily tasks, allowing nursing assistants and orderlies to consciously avoid adopting forced postures that are detrimental to their health.

In this line of research, we also found the study by Owlia, Kamachi and Dutta [68] that confirmed that the feedback provided by a wearable device (PostureCoach) could improve the posture of nursing staff in patient-handling tasks. Compared to wearable devices, the advantages of the postural feedback we use are low-cost, have a small space requirement, 
high adaptability, and make you aware of your own problems, so that safe postural habits can be maintained for a longer period of time.

Postural feedback is an intervention method that gives participants the opportunity to talk and participate. The measures are not fully formulated by ergonomists. In the postural-feedback meeting, professionals actively participated in the discussion of postural risks by watching their own videos and proposing feasible improvement measures based on their in-depth knowledge of their work content and environment.

Occupational safety and health $(\mathrm{OSH})$ [69] stresses the importance of worker participation in ergonomic interventions, noting that it is easier to accept and implement this way. Furthermore, Burgess-Limerick [70] concluded, by reviewing evidence from different sectors, that participatory ergonomic interventions are more likely to be the best solution to reduce the incidence of work-related MSDs.

In addition, the impact of warm-up and stretching exercises should be added. Their positive role in the prevention of MSDs has been confirmed in some MSD studies [33,58], including increased muscle strength and injury prevention.

With respect to the lack of significant improvement in group B (forearms, arms, wrists and grip), this may be due to the fact that most of the patients assessed were seated or lying down, and the professionals must extend their arms to hold or carry them; added to this, on numerous occasions the grip is the patient's human body or clothing, making it very complicated, if not impossible to improve these conditions in daily tasks with the conditions they have. In any case, we should study this result in depth in case there is any way to improve based on tools that provide help in the transfer of patients.

Finally, it should be noted that, despite the eight months that passed from the preassessment to the post-assessment, the results are significant, which implies that the intervention has been effective and stable over time, since the interval of months has been sufficiently long enough to talk about the stability of the results. However, this brings with it the loss of some individuals from the sample, since this is a type of work that usually involves a lot of rotation between shifts and services within the hospital, and this has been reflected in the final sample.

\section{Advantages and Limitations}

First, one of the advantages is the randomized controlled trial design; participants were completely randomly assigned to the intervention and control groups, thus avoiding selection bias. The control group reflects the rigor and distinction of the experiment. Second, because there were no significant differences in sociodemographic characteristics between the control group and the intervention group, the influence of other possible interfering factors on the test results was avoided.

However, we still need to consider some limitations and resolve them in future research. The first is the sample size; we invited all nursing assistants and orderlies who worked on the assessment and intervention days to participate in the study. However, due to the complexity of the work of the health personnel, the final sample size was not very large. Another limitation is that the participants in this study are mostly women (76.4\%). Given that nearly 70\% of Andalusian Health Service workers are women, the sex ratio of the participants in the study respects this particularity of the general population. Even so, it will make sense to apply this intervention to other masculine sectors in future research.

Finally, the limitations of the assessment method should be mentioned. Although we have proven the effectiveness of the multi-component intervention, the specific impact of each part is beyond the scope of our research. It is recommended that future studies apply this intervention plan to more units and follow up the long-term impact or a longitudinal study on the rate of sick leave due to musculoskeletal disorders. In addition, future research is recommended to explore the intermediate mechanism of the intervention plan of each of the components included in the study in order to discover the impact of each part on the results and the interaction between them. 


\section{Conclusions}

Our study shows that a multi-component intervention can significantly reduce ergonomic risk for nursing assistants and orderlies working in the hospital environment. The novel component of this study, postural feedback, allows professionals to participate in risk assessment actively and propose improvement measures, which seems to be related to the involvement of workers in this intervention and results in its implementation and durability over time. This intervention program has low cost and high applicability. In addition, it has low requirements for working environment and working conditions and high reproducibility. Further pilot studies can be conducted in more hospitals and nursing homes with larger samples, and a periodic follow-up study is recommended to observe the long-term impact on reducing the incidence of musculoskeletal disorders.

Author Contributions: Conceptualization, C.O.H. and I.M.R.; methodology, S.L.; software, S.L.; validation, M.D.M.R., I.M.R. and C.O.H.; formal analysis, S.L.; investigation, S.L.; data curation, C.O.H.; writing—original draft preparation, S.L., C.O.H. and I.M.R.; writing—review and editing, M.D.M.R.; visualization, M.D.M.R.; supervision, C.O.H., M.D.M.R. and I.M.R.; project administration, I.M.R. All authors have read and agreed to the published version of the manuscript.

Funding: This research was funded by the Regional Health Department [grant number: PS-0283-335 2016]. The content is solely the responsibility of the authors and does not necessarily represent the 336 official views of the Regional Health Department.

Institutional Review Board Statement: The study was conducted in accordance with the Declaration of Helsinki, and approved by the Andalusian Research Ethics Committee (REC of the Virgen Macarena-Virgen del Rocio university hospitals: d9b449426c41062448a2d8be713a0b063741ae96).

Informed Consent Statement: Informed consent was obtained from all subjects involved in the study.

Data Availability Statement: The data presented in this study are openly available in Mendeley Data at doi:10.17632/8ph6zcd6p3.1.

Acknowledgments: There are many people who have contributed to this research, and we would like to express our gratitude to them. We sincerely thank all participants for their cooperation in the research. We also wanted to thank the hospital's health and safety team for managing the training rooms and offering us materials. We are grateful to Marchante, A. for his help in data collection and video recording. Finally, we would like to thank the administrative team of Andalusian School of Public Health and Complutense University of Madrid for their approval and full support of this work.

Conflicts of Interest: The authors declare no conflict of interest.

\section{References}

1. Coluci, M.Z.O.; Alexandre, N.M.C. Job factors related to musculoskeletal symptoms among nursing personnel—A review. Work 2012, 41, 2516-2520. [CrossRef]

2. $\quad$ El-Sallamy, R.M.; Zayed, H.; Saied, S.; Shehata, W. Work-Related Musculoskeletal Disorders among Nursing Staff of Tanta University Hospitals: Pattern, Risk Factors, and Coping Strategies. Community Med. 2019, 37, 51-61.

3. Occupational Health and Safety Risks in the Healthcare Sector. Publications Office of the EU. 2014. Available online: https: / / op.europa.eu/en/publication-detail/- / publication/b29abb0a-f41e-4cb4-b787-4538ac5f0238 (accessed on 20 October 2020).

4. Guan, J.; Wu, D.; Xie, X.; Duan, L.; Yuan, D.; Lin, H.; Liu, L.; Li, J. Occupational Factors Causing Pain among Nurses in Mainland China. Med. Sci. Monit. 2019, 25, 1071-1077. [CrossRef] [PubMed]

5. Viester, L.; Verhagen, E.A.; Hengel, K.M.O.; Koppes, L.L.; Van Der Beek, A.J.; Bongers, P.M. The Relation between Body Mass Index and Musculoskeletal Symptoms in the Working Population. BMC Musculoskelet. Disord. 2013, 14, 238. [CrossRef] [PubMed]

6. Bernal, D.; Campos-Serna, J.; Tobias, A.; Vargas-Prada, S.; Benavides, F.G.; Serra, C. Work-Related Psychosocial Risk Factors and Musculoskeletal Disorders in Hospital Nurses and Nursing Aides: A Systematic Review and Meta-Analysis. Int. J. Nurs. Stud. 2015, 52, 635-648. [CrossRef] [PubMed]

7. Lee, S.J.; Faucett, J.; Gillen, M.; Krause, N.; Landry, L. Factors Associated with Safe Patient Handling Behaviors among Critical Care Nurses. Am. J. Ind. Med. 2010, 53, 886-897. [CrossRef] [PubMed]

8. World Health Organization. Musculoskeletal Conditions. Available online: https://www.who.int/news-room/fact-sheets/ detail/musculoskeletal-conditions (accessed on 2 January 2022).

9. Lezin, N.; Walkins Castillo, S. The Burden of Musculoskeletal Disorders on Americans-Opportunities for Action; The United States Bone and Joint Initiative (USBJI): Rosemont, IL, USA, 2016. 
10. De Kok, J.; Vroonhof, P.; Snijders, J.; Roullis, G.; Clarke, M.; Peereboom, K.; van Dorst, P.; Isusi, I. Work-Related Musculoskeletal Disorders: Prevalence, Costs and Demographics in the EU; European Agency for Safety and Health at Work: Bilbao, Spain, 2019.

11. Davis, K.G.; Kotowski, S.E. Prevalence of Musculoskeletal Disorders for Nurses in Hospitals, Long-Term Care Facilities, and Home Health Care: A Comprehensive Review. Hum. Factors 2015, 57, 754-792. [CrossRef] [PubMed]

12. Carugno, M.; Pesatori, A.C.; Ferrario, M.M.; Ferrari, A.L.; da Silva, F.J.; Martins, A.C.; Felli, V.E.A.; Coggon, D.; Bonzini, M. Physical and Psychosocial Risk Factors for Musculoskeletal Disorders in Brazilian and Italian Nurse. Cad. De Saude Publica 2012, 28, 1632-1642. [CrossRef]

13. Nützi, M.; Koch, P.; Baur, H.; Elfering, A. Work-Family Conflict, Task Interruptions, and Influence at Work Predict Musculoskeletal Pain in Operating Room Nurses. Saf. Health Work 2015, 6, 329-337. [CrossRef]

14. Harcombe, H.; Herbison, G.P.; McBride, D.; Derrett, S. Musculoskeletal Disorders among Nurses Compared with Two Other Occupational Groups. Occup. Med. 2014, 64, 601-607. [CrossRef]

15. Akbari, H.; Akbari, H.; Bagheri Hossein Abadi, M.; Gholami Fesharaki, M.; Ghasemi, M. Assessing the Risk of Manual Handling of Patients and Its Relationship with the Prevalence of Musculoskeletal Disorders among Nursing Staff: Performance Evaluation of the MAPO and PTAI Methods. Iran. Red Crescent Med. J. 2017, 19, 8. [CrossRef]

16. Serranheira, F.; Sousa-Uva, M.; Sousa-Uva, A. Hospital Nurses Tasks and Work-Related Musculoskeletal Disorders Symptoms: A Detailed Analysis. Work 2015, 51, 401-409. [CrossRef] [PubMed]

17. Heidari, M.; Borujeni, M.G.; Rezaei, P.; Abyaneh, S.K. Work-Related Musculoskeletal Disorders and Their Associated Factors in Nurses: A Cross-Sectional Study in Iran. Malays. J. Med. Sci. 2019, 26, 122-130. [CrossRef] [PubMed]

18. Sezgin, D.; Esin, M.N. Predisposing Factors for Musculoskeletal Symptoms in Intensive Care Unit Nurses. Int. Nurs. Rev. 2015, 62, 92-101. [CrossRef]

19. European Agency for Safety and Health at Work (EU-OSHA). Work-Related Musculoskeletal Disorders: Facts and Figures-Synthesis Report of 10 EU Member States Reports, 2020 (AT, DE, DK, ES, FI, FR, HU, IT, NL and SE); European Agency for Safety and Health at Work: Bilbao, Spain, 2020.

20. Ergonomics and Musculoskeletal Disorders.The National Institute for Occupational Safety and Health (NIOSH) CDC. 2018. Available online: https://www.cdc.gov/niosh/topics/ergonomics (accessed on 3 November 2020).

21. Nourollahi, M.; Afshari, D.; Dianat, I. Awkward Trunk Postures and Their Relationship with Low Back Pain in Hospital Nurses. Work 2018, 59, 317-323. [CrossRef]

22. Freitag, S.; Fincke-Junod, I.; Seddouki, R.; Dulon, M.; Hermanns, I.; Kersten, J.F.; Larsson, T.J.; Nienhaus, A. Frequent Bending-An Underestimated Burden in Nursing Professions. Ann. Occup. Hyg. 2012, 56, 697-707. [CrossRef] [PubMed]

23. Caponecchia, C.; Coman, R.L.; Gopaldasani, V.; Mayland, E.C.; Campbell, L. Musculoskeletal Disorders in Aged Care Workers: A Systematic Review of Contributing Factors and Interventions. Int. J. Nurs. Stud. 2020, 110, 103715. [CrossRef]

24. Da Costa, B.R.; Vieira, E.R. Risk Factors for Work-Related Musculoskeletal Disorders: A Systematic Review of Recent Longitudinal Studies. Am. J. Ind. Med. 2009, 53, 285-323. [CrossRef] [PubMed]

25. Warren, G. Moving and Handling: Reducing Risk through Assessment. Nurs. Stand. 2016, 30, 49-58. [CrossRef]

26. Samaei, S.E.; Mostafaee, M.; Jafarpoor, H.; Hosseinabadi, M.B. Effects of Patient-Handling and Individual Factors on the Prevalence of Low Back Pain among Nursing Personnel. Work 2017, 56, 551-561. [CrossRef] [PubMed]

27. Rypicz, Ł.; Karniej, P.; Witczak, I.; Kołcz, A. Evaluation of the Occurrence of Work-Related Musculoskeletal Pain among Anesthesiology, Intensive Care, and Surgical Nurses: An Observational and Descriptive Study. Nurs. Health Sci. 2020, 22, 1056-1064. [CrossRef] [PubMed]

28. Kucera, K.L.; Schoenfisch, A.L.; McIlvaine, J.; Becherer, L.; James, T.; Yeung, Y.L.; Avent, S.; Lipscomb, H.J. Factors Associated with Lift Equipment Use during Patient Lifts and Transfers by Hospital Nurses and Nursing Care Assistants: A Prospective Observational Cohort Study. Int. J. Nurs. Stud. 2019, 91, 35-46. [CrossRef]

29. Petit, A.; Mairiaux, P.; Desarmenien, A.; Meyer, J.-P.; Roquelaure, Y. French Good Practice Guidelines for Management of the Risk of Low Back Pain among Workers Exposed to Manual Material Handling: Hierarchical Strategy of Risk Assessment of Work Situations. Work 2016, 53, 845-850. [CrossRef]

30. Hegewald, J.; Berge, W.; Heinrich, P.; Staudte, R.; Freiberg, A.; Scharfe, J.; Girbig, M.; Nienhaus, A.; Seidler, A. Do Technical Aids for Patient Handling Prevent Musculoskeletal Complaints in Health Care Workers?-A Systematic Review of Intervention Studies. Int. J. Environ. Res. Public Health 2018, 15, 476. [CrossRef] [PubMed]

31. Freiberg, A.; Euler, U.; Girbig, M.; Nienhaus, A.; Freitag, S.; Seidler, A. Does the Use of Small Aids during Patient Handling Activities Lead to a Decreased Occurrence of Musculoskeletal Complaints and Diseases? A Systematic Review. Int. Arch. Occup. Environ. Health 2016, 89, 547-559. [CrossRef]

32. Stock, S.R.; Nicolakakis, N.; Vézina, N.; Vézina, M.; Gilbert, L.; Turcot, A.; Sultan-Taïeb, H.; Sinden, K.; Denis, M.A.; Delga, C.; et al. Are Work Organization Interventions Effective in Preventing or Reducing Work-Related Musculoskeletal Disorders? A Systematic Review of the Literature. Scand. J. Work Environ. Health 2018, 44, 113-133. [CrossRef]

33. Gasibat, Q.; bin Simbak, N.; Abd Aziz, A. Stretching Exercises to Prevent Work-Related Musculoskeletal Disorders-A Review Article. Am. J. Sports Sci. Med. 2017, 5, 27-37. [CrossRef]

34. Chanchai, W.; Songkham, W.; Ketsomporn, P.; Sappakitchanchai, P.; Siriwong, W.; Robson, M.G. The Impact of an Ergonomics Intervention on Psychosocial Factors and Musculoskeletal Symptoms among Thai Hospital Orderlies. Int. J. Environ. Res. Public Health 2016, 13, 464. [CrossRef] [PubMed] 
35. Savarise, M.T.; Savarise, Y.; Buhavac, M.; Blumhagen, J.; Glasgow, R.E.; Marcus, R.; Magel, J.S. Structured Postural Education Program to Improve Ergonomics and Reduce Work-Related Musculoskeletal Disorders among Surgeons. J. Am. Coll. Surg. 2020, 231, e51-e52. [CrossRef]

36. Dennerlein, J.T.; Hopcia, K.; Sembajwe, G.; Kenwood, C.; Stoddard, A.M.; Tveito, T.H.; Hashimoto, D.M.; Sorensen, G. Ergonomic Practices within Patient Care Units Are Associated with Musculoskeletal Pain and Limitations. Am. J. Ind. Med. 2012, 55, 107-116. [CrossRef] [PubMed]

37. Garg, A.; Kapellusch, J.M. Long-Term Efficacy of an Ergonomics Program That Includes Patient-Handling Devices on Reducing Musculoskeletal Injuries to Nursing Personnel. Hum. Factors 2012, 54, 608-625. [CrossRef] [PubMed]

38. Hoe, V.C.; Urquhart, D.M.; Kelsall, H.L.; Zamri, E.N.; Sim, M.R. Ergonomic Interventions for Preventing Work-Related Musculoskeletal Disorders of the Upper Limb and Neck among Office Workers. Cochrane Database Syst. Rev. 2018, 10, 1-135. [CrossRef] [PubMed]

39. Rodrigues Ferreira Faisting, A.L.; de Oliveira Sato, T. Effectiveness of Ergonomic Training to Reduce Physical Demands and Musculoskeletal Symptoms-An Overview of Systematic Reviews. Int. J. Ind. Ergon. 2019, 74, 102845. [CrossRef]

40. Andersen, L.L.; Burdorf, A.; Fallentin, N.; Persson, R.; Jakobsen, M.D.; Mortensen, O.S.; Clausen, T.; Holtermann, A. Patient Transfers and Assistive Devices: Prospective Cohort Study on the Risk for Occupational Back Injury among Healthcare Workers. Scand. J. Work Environ. Health 2014, 40, 74-81. [CrossRef]

41. Tullar, J.M.; Brewer, S.; Amick, B.C.; Irvin, E.; Mahood, Q.; Pompeii, L.A.; Wang, A.; van Eerd, D.; Gimeno, D.; Evanoff, B. Occupational Safety and Health Interventions to Reduce Musculoskeletal Symptoms in the Health Care Sector. J. Occup. Rehabil. 2010, 20, 199-219. [CrossRef]

42. Risør, B.W.; Casper, S.D.; Andersen, L.L.; Sørensen, J. A Multi-Component Patient-Handling Intervention Improves Attitudes and Behaviors for Safe Patient Handling and Reduces Aggression Experienced by Nursing Staff: A Controlled before-after Study. Appl. Ergon. 2017, 60, 74-82. [CrossRef]

43. Nelson, A.; Matz, M.; Chen, F.; Siddharthan, K.; Lloyd, J.; Fragala, G. Development and Evaluation of a Multifaceted Ergonomics Program to Prevent Injuries Associated with Patient Handling Tasks. Int. J. Nurs. Stud. 2006, 43, 717-733. [CrossRef]

44. Ratzon, N.Z.; Bar-Niv, N.A.; Froom, P. The Effect of a Structured Personalized Ergonomic Intervention Program for Hospital Nurses with Reported Musculoskeletal Pain: An Assigned Randomized Control Trial. Work 2016, 54, 367-377. [CrossRef]

45. Martimo, K.-P.; Shiri, R.; Miranda, H.; Ketola, R.; Varonen, H.; Viikari-Juntura, E. Effectiveness of an Ergonomic Intervention on the Productivity of Workers with Upper-Extremity Disorders-A Randomized Controlled Trial. Scand. J. Work Environ. Health 2010, 36, 25-33. [CrossRef]

46. Olinski, C.; Norton, C.E. Implementation of a Safe Patient Handling Program in a Multihospital Health System from Inception to Sustainability: Successes over 8 Years and Ongoing Challenges. Workplace Heal. Saf. 2017, 65, 546-559. [CrossRef]

47. Yang, S.; Li, L.; Wang, L.; Zeng, J.; Yan, B.; Li, Y. Effectiveness of a Multidimensional Intervention Program in Improving Occupational Musculoskeletal Disorders among Intensive Care Unit Nurses: A Cluster-Controlled Trial with Follow-up at 3 and 6 Months. BMC Nurs. 2021, 20, 46. [CrossRef] [PubMed]

48. Richardson, A.; McNoe, B.; Derrett, S.; Harcombe, H. Interventions to Prevent and Reduce the Impact of Musculoskeletal Injuries among Nurses: A Systematic Review. Int. J. Nurs. Stud. 2018, 82, 58-67. [CrossRef]

49. Van Hoof, W.; O'Sullivan, K.; O'Keeffe, M.; Verschueren, S.; O'Sullivan, P.; Dankaerts, W. The Efficacy of Interventions for Low Back Pain in Nurses: A Systematic Review. Int. J. Nurs. Stud. 2018, 77, 222-231. [CrossRef] [PubMed]

50. Weir, C.B.; Jan, A. BMI Classification Percentile and Cut Off Points; StatPearls Publishing: Treasure Island, FL, USA, 2019.

51. Hignett, S.; McAtamney, L. Rapid Entire Body Assessment (REBA). Appl. Ergon. 2000, 31, 201-205. [CrossRef]

52. Schwartz, A.H.; Albin, T.J.; Gerberich, S.G. Intra-Rater and Inter-Rater Reliability of the Rapid Entire Body Assessment (REBA) Tool. Int. J. Ind. Ergon. 2019, 71, 111. [CrossRef]

53. Diego, J.A. Postural Evaluation Using the REBA Method. Ergonauts, Polytechnic University of Valencia. 2015. Available online: http:/ / www.ergonautas.upv.es/metodos/reba/reba-ayuda.php (accessed on 2 January 2022).

54. Al Madani, D.; Dababneh, A. Rapid Entire Body Assessment: A Literature Review. Am. J. Eng. Appl. Sci. 2016, 9, 107-118. [CrossRef]

55. Khan, R.; Scaffidi, M.A.; Satchwell, J.; Gimpaya, N.; Lee, W.; Genis, S.; Tham, D.; Saperia, J.; Al-Mazroui, A.; Walsh, C.M.; et al. Impact of a Simulation-Based Ergonomic Training Curriculum on Work-Related Musculoskeletal Injury Risk in Colonoscopy. Gastrointest. Endosc. 2020, 92, 1070-1080. [CrossRef] [PubMed]

56. Hita-Gutiérrez, M.; Gómez-Galán, M.; Díaz-Pérez, M.; Callejón-Ferre, Á.J. An Overview of Reba Method Applications in the World. Int. J. Environ. Res. Public Health 2020, 17, 2635. [CrossRef]

57. Beyan, A.C.; Dilek, B.; Demiral, Y. The Effects of Multifaceted Ergonomic Interventions on Musculoskeletal Complaints in Intensive Care Units. Int. J. Environ. Res. Public Health 2020, 17, 3719. [CrossRef]

58. Moreira, R.F.C.; Moriguchi, C.S.; Carnaz, L.; Foltran, F.A.; Silva, L.C.C.B.; Coury, H.J.C.G. Effects of a Workplace Exercise Program on Physical Capacity and Lower Back Symptoms in Hospital Nursing Assistants: A Randomized Controlled Trial. Int. Arch. Occup. Environ. Health 2021, 94, 275-284. [CrossRef]

59. Jakobsen, M.D.; Sundstrup, E.; Brandt, M.; Jay, K.; Aagaard, P.; Andersen, L.L. Physical Exercise at the Workplace Reduces Perceived Physical Exertion during Healthcare Work: Cluster Randomized Controlled Trial. Scand. J. Public Health 2015, 43, 713-720. [CrossRef] [PubMed] 
60. Lee, H.; Chae, D.; Cho, S.; Kim, J.; Yoo, R. Influence of a Community-Based Stretching Intervention on the Health Outcomes among Korean-Chinese Female Migrant Workers in South Korea: A Randomized Prospective Trial. Jpn. J. Nurs. Sci. 2017, 14, 277-287. [CrossRef]

61. Lee, E.W.C.; Fok, J.P.C.; Lam, A.T.; Law, R.K.Y.; Szeto, G.P.Y.; Li, P.P.K. The Application of Participatory Ergonomics in a Healthcare Setting in Hong Kong. Work 2014, 48, 511-519. [CrossRef]

62. Soler-Font, M.; Ramada, J.M.; van Zon, S.K.R.; Almansa, J.; Bültmann, U.; Serra, C.; Merelles, A.; Peña, P.; Vargas-Prada, S. Multifaceted Intervention for the Prevention and Management of Musculoskeletal Pain in Nursing Staff: Results of a Cluster Randomized Controlled Trial. PLoS ONE 2019, 14, e0225198. [CrossRef]

63. Serra, C.; Soler-Font, M.; García, A.M.; Peña, P.; Vargas-Prada, S.; Ramada, J.M. Prevention and Management of Musculoskeletal Pain in Nursing Staff by a Multifaceted Intervention in the Workplace: Design of a Cluster Randomized Controlled Trial with Effectiveness, Process and Economic Evaluation (INTEVAL_Spain). BMC Public Health 2019, 19, 348. [CrossRef] [PubMed]

64. Shojaei, S.; Tavafian, S.S.; Jamshidi, A.R.; Wagner, J. A Multidisciplinary Workplace Intervention for Chronic Low Back Pain among Nursing Assistants in Iran. Asian Spine J. 2017, 11, 419-426. [CrossRef] [PubMed]

65. Carta, A.; Parmigiani, F.; Roversi, A.; Rossato, R.; Milini, C.; Parrinello, G.; Apostoli, P.; Alessio, L.; Porru, S. Training in Safer and Healthier Patient Handling Techniques. Br. J. Nurs. 2010, 19, 576-582. [CrossRef] [PubMed]

66. Abdollahi, T.; Razi, S.P.; Pahlevan, D.; Yekaninejad, M.S.; Amaniyan, S.; Sieloff, C.L.; Vaismoradi, M. Effect of an Ergonomics Educational Program on Musculoskeletal Disorders in Nursing Staff Working in the Operating Room: A Quasi-Randomized Controlled Clinical Trial. Int. J. Environ. Res. Public Health 2020, 17, 7333. [CrossRef]

67. Ziam, S.; Laroche, E.; Lakhal, S.; Alderson, M.; Gagné, C. Application of MSD Prevention Practices by Nursing Staff Working in Healthcare Settings. Int. J. Ind. Ergon. 2020, 77, 102959. [CrossRef]

68. Owlia, M.; Kamachi, M.; Dutta, T. Reducing Lumbar Spine Flexion Using Real-Time Biofeedback during Patient Handling Tasks. Work 2020, 66, 41-51. [CrossRef]

69. Koningsveld, E.; de Looze, M. Approaches to Work Design-OSHWiki. 2017. Available online: https://oshwiki.eu/wiki/ Approaches_to_work_design\#Participatory_ergonomics (accessed on 12 August 2021).

70. Burgess-Limerick, R. Participatory Ergonomics: Evidence and Implementation Lessons. Appl. Ergon. 2018, 68, 289-293. [CrossRef] [PubMed] 